\title{
Fruit and Vegetable Perceptions Among Caregivers of American Indian Toddlers and Community Stakeholders: a Qualitative Study
}

\author{
Rachel C. Sinley • Julie A. Albrecht
}

Received: 17 September 2014 / Revised: 10 November 2014 / Accepted: 5 December 2014 / Published online: 21 January 2015

(C) W. Montague Cobb-NMA Health Institute 2015

\begin{abstract}
American Indians experience higher rates of obesity than any other ethnic group living in the USA. This disparity begins to develop in early childhood, and the excess weight carried by American Indian children contributes to health conditions that can affect their quality of life by the time they enter preschool. These children consume less than recommended amounts of fruits and vegetables, a dietary pattern that may be related to the development of obesity and other health conditions. This qualitative study explored the fruit and vegetable intake of American Indian toddlers through use of the information-motivation-behavioral skills (IMB) model. Focus groups with caregivers of American Indian toddlers and interviews with stakeholders in American Indian communities were conducted to investigate perceptions of knowledge, motivational, and behavioral skills related to the fruit and vegetable intake of American Indian toddlers. Study participants communicated that peer support, food insecurities, cultural norms, self-efficacy, and skills to prepare fruits and vegetables impact their ability to provide fruits and vegetables to toddlers. Study participants expressed a desire to increase their knowledge regarding fruits and vegetables, including variety, benefits, and recommendations for consumption. Findings from this qualitative study provide essential insights into perceptions of fruits and vegetables among caregivers of American Indian toddlers and stakeholders in American Indian communities. Future research will utilize these findings to develop a culturally appropriate IMB-model-
\end{abstract}

\footnotetext{
R. C. Sinley

Department of Nutrition and Health Sciences, University of Nebraska-Lincoln, 312 LEV, Lincoln, NE 68583-3727, USA e-mail: rlund3880@msn.com
}

J. A. Albrecht $(\square)$

Department of Nutrition and Health Sciences, University of Nebraska-Lincoln, 119 LEV, Lincoln, NE 68583-0807, USA e-mail: jalbrecht1@unl.edu based fruit and vegetable-focused nutrition education program for American Indian families.

Keywords American Indian · Toddlers · Qualitative · Fruits · Vegetables

\section{Introduction}

The Centers for Disease Control (CDC) express obesity in terms of body mass index (BMI), where weight in kilograms is divided by height in meters squared $\left(\mathrm{kg} / \mathrm{m}^{2}\right)$ [1]. Overweight is classified as a BMI between 25.0 and 29.9; obesity is classified as a BMI greater than or equal to 30.0 ; and extreme obesity is classified as a BMI greater than or equal to 40.0 [1]. These values have been established due to their associations with increased rates of comorbidities, such as heart disease and diabetes [2]. American Indian children are disproportionately affected by obesity in comparison to other groups. While estimates of childhood overweight and obesity are high among all ethnic groups, rates among American Indian children exceed those of all other ethnicities combined [3-5]. Data from the CDC conclude that between 2003 and 2010 , the prevalence of obesity actually decreased among all ethnic groups except the American Indian population [6]. In comparison to children in other ethnic groups, American Indian children also have a greater risk of cardiovascular risk factors, diabetes, and premature death [7]. This disparity is likely a result of numerous intersecting factors, and it has been suggested that lifestyle practices, such as physical inactivity and excessive caloric intake are contributing factors [7, 8].

The obesity disparity that has been documented with the American Indian population often develops in early childhood, as early as 12 months of age [8], with American Indian infants exhibiting high rates of obesity that correlate to overweight status later in childhood. Considering the early 
development of overweight, obesity, and other nutritionrelated chronic diseases among American Indian children and the extreme disparity that exists with this population compared to other ethnic groups, interventions need to be developed and implemented to improve the health status of American Indian children $[8,9]$.

Few nutrition interventions have been implemented among young American Indian children [10]. Research into the dietary behaviors of American Indians is also somewhat limited, as many individuals live in rural tribal reservations exempt from national surveys [11]. There are also issues of tremendous variety within the diets of American Indians, as well as concerns of mistrust among the population, which can make gathering dietary data challenging [12]. However, recent quantitative investigations into the diets of American Indian individuals have shown inadequate consumption of fruits and vegetables [13-15].

The health benefits associated with adequate fruit and vegetable intake include prevention of many of the chronic conditions that American Indians disproportionately suffer from, such as stroke, cardiovascular disease, and obesity [16-19]. Therefore, it is imperative to explore the phenomenon of inadequate fruit and vegetable intake among American Indian children to inform future interventions to address intake and improve health conditions of this population.

Prior to developing nutrition interventions, we need to understand the specific population and any attitudes, beliefs, or values that may impact the behavior being addressed [20]. Few studies have been conducted that investigate elements of the dietary behaviors of American Indian toddlers or this ethnic group in general. Researchers have concluded that fruit and vegetable intakes among American Indian groups is related to social supports [11], self-efficacy, and knowledge [21] and perceptions to healthy eating [22]. The informationmotivation-behavioral skills (IMB) model addresses these issues within its three constructs. This general model of health behavior change has been used to frame and create theoretically and empirically based health risk reduction interventions. The IMB model focuses on the set of informational, motivational, and behavioral skills associated with successful practice of preventive health-related behaviors [23]. The information construct refers to highly relevant knowledge about the health behavior. The motivation construct embodies a range of perceptions related to the behavior, including social and environmental supports and personal attitudes. The behavioral skills construct is based on the concept of selfefficacy but also takes actual skill level into account [20]. The model postulates that when individuals are well-informed, motivated to act, and possess the necessary behavioral skills required to act effectively, they will likely initiate and maintain a health behavior [24].

Dietary habits are established early in childhood, making parents and caregivers key role models in forming these habits and driving behavioral change [25-27].Community also plays an important role in supporting the health-related behaviors of American Indian children [28]. Thus, the purpose of this study was to explore the topic of fruit and vegetable intake of American Indian toddlers within the framework of the IMB model by conducting focus groups with primary caregivers and interviews with community stakeholders.

\section{Methods}

\section{Participants}

Study participants were primary caregivers of American Indian toddlers, (ages 2 to 5 years old) and stakeholders in American Indian communities. Primary caregivers were parents or any individual who self-identified as being responsible for providing meals and health care to the child. These inclusion criteria were used to ensure that participants could provide accurate information regarding dietary preferences and health needs of the children in question. It also allowed for grandparents or other caregivers to participate, a necessary consideration as American Indian grandmothers are often the primary caregiver of their grandchildren [29], which may be a result of socioeconomic challenges or cultural norms [30]. The caregivers identified the child as being of American Indian descent.

Many American Indian tribal communities are bound together by a sense of cultural ties and community pride, with the notion that all members are connected in a circular fashion [31]. Community stakeholders were identified as individuals who have connections in the community and experience working with American Indian toddlers and families on health- and nutrition-related issues, such as WIC educators, Head Start staff, and extension educators. All study participants were English proficient.

\section{Study Setting}

This study was conducted on two tribal reservations and in three urban settings servicing the American Indian community in Nebraska. There are approximately 5.2 million individuals who identify themselves as American Indian nationwide [32]. Of the estimated 1,855,525 individuals living in Nebraska, $1.3 \%$ identify themselves as being of American Indian descent [33]. Study participants represented several tribes, including Omaha, Santee Sioux, Ponca, and Winnebago. This study was reviewed and approved by the University of Nebraska-Lincoln Institutional Review Board (IRB) and by tribal leaders on the reservations where the study took place. Special approval was obtained from IRB to work with caregivers under the age of 19 to ensure this study obtained perspectives of young caregivers. 


\section{Recruitment}

The researcher spent extensive time in the communities prior to recruitment to aid in the establishment of trust. Recruitment took place at community health fairs and through flyers, online social media, and newsletters for American Indian community centers and reservations. Non-probability convenience and snowball sampling methods were used, in which the researcher recruited interested participants at a variety of community events who then recruited additional participants from their networks [34]. Researcher contact information was given to interested individuals, and preliminary screening was conducted over the phone to confirm that the participant was the primary caregiver of an American Indian child between the ages of 2 and 5 years old. The participants of the structured interviews were recruited via referrals from local extension offices, Indian Health Service hospitals, and community centers using criterion and maximum variation sampling [34]. By employing this sampling technique, individuals were selected that varied in their experiences with American Indian toddlers and families which allowed for an in-depth understanding of the complexity of the issue being explored [34]. Participants of the focus groups received a $\$ 25$ gift card and a light lunch for their participation in the study. Participants of the interviews received a $\$ 10$ gift card for their participation.

\section{Procedures}

\section{Focus Groups}

The focus groups were held in community settings such as community colleges and Head Start centers. Each focus group has between 3 and 12 participants. Sessions lasted between 35 and $75 \mathrm{~min}$ in duration. Informed consent was reviewed and obtained in writing prior to initiating each focus group. Participants completed a demographic questionnaire and the "ByMeal Fruit and Vegetable Screener," a validated fruit and vegetable food frequency questionnaire [35] in which they estimated their child's fruit and vegetable intake. If the focus group participant indicated that they had more than one child between the ages of 2 and 5, they were instructed to fill out the questionnaire in response to the youngest child in the 2 to 5 age range. After completion of the questionnaire, a trained facilitator introduced herself and explained the purposes of the study and the logistics of the focus group discussion. Participants introduced themselves using only first names. All focus group sessions were digitally recorded and transcribed.

A written script was used to guide the focus group discussion. The focus group questions were based on the IMB model constructs to extract information about perceptions related to fruit and vegetable intake among American Indian toddlers and caregivers. These questions were reviewed by community stakeholders and revised accordingly. The focus group sessions followed standard focus group procedures [36], which first began with an ice-breaker question, moved to general questions regarding fruits and vegetables, and then became more specific regarding perceptions, challenges, and knowledge. To increase the trustworthiness of the findings [37], at the conclusion of each focus group, the facilitator summarized the session and asked for confirmation and clarification of these statements.

\section{Interviews}

Interviews were held in locations selected by the interviewee and were typically private rooms in office buildings. Sessions lasted between 20 and $60 \mathrm{~min}$ in duration. Informed consent was reviewed and obtained in writing prior to the start of each interview. Interviews were digitally recorded and transcribed. Notes of key topics were taken to aid in analysis. An interview protocol was used to guide questioning [38]. The sessions started with ice-breaker questions and then continued toward descriptive questions regarding the interviewees' experiences working with American Indian families with toddlers. The interviews concluded with questions regarding challenges and perceptions to addressing nutrition and health in American Indian communities. Table 1 lists examples of questions used in both the focus group and interview sessions. Focus groups and interviews were conducted until it was determined that saturation was reached and no new information was being gathered [36].

\section{Data Analysis}

Audio recordings were transcribed verbatim and entered into the QSR NVivo software package (NVivo version 9, QSR International, Melbourne, Australia, 2010). Transcripts were

Table 1 Sample focus group and interview questions from guide

Focus group questions

Ice-breaker When I say fruits and vegetables, what comes to mind?

Attitudes How do you think your child feels about eating fruits and vegetables?

-Why do you think they feel that way?

Challenges What are some things that make it difficult for you to offer your child fruits and vegetables?

Knowledge What types of things would you like to learn about fruits and vegetables?

Interview questions

Ice-breaker Tell me, what is your favorite thing about this job?

Experiences Tell me more about your interactions with American Indian families.

Attitudes What are some nutrition-related perceptions that you encounter?

Challenges What challenges do you think exist in addressing the health of the American Indian population? 
analyzed using qualitative content analysis strategies [39]. Each transcript was analyzed first as an individual case. After each transcript was analyzed, the focus group transcripts were analyzed together for common themes, as were the interview transcripts. Finally, the focus group and interview transcripts were analyzed together and assessed for concordance and discordance.

The researcher engaged in memoing the transcripts and categorized these notes using open coding, a process in which broad trends in the data are conceptualized and labeled [40]. A coding manual was developed, which provided descriptions for each identified code. Codes were grouped into larger categories identified as themes. Two additional members of the study team jointly examined the transcripts and engaged in open coding and theming of the data. The researchers compared and discussed themes and resolved discrepancies to address inter-rater reliability. The developed themes were then assessed for applicability to the IMB model. The themes were divided into sub-themes, with the IMB model constructs as the primary themes. It is important to note that, while the research team did use the IMB model to explain the results, the use of open coding ensured that themes emerged that were beyond the scope of the IMB model. The fruit and vegetable food frequency questionnaire was scored using guidelines from the National Cancer Institute [41], and daily averages of intakes were calculated.

\section{Results}

Six focus groups $(N=45)$ and ten individual interviews were conducted. Focus group participants were predominately female $(93.33 \%)$ and ranged in age from 15 to 64 years old with a mean age of 38.15 (s.d. \pm 15.29 ). Participants had an average of 3.44 children in their care and $46.67 \%$ reported some posthigh school training or education. Average reported intake of fruits (excluding $100 \%$ juice) was 0.79 cups (s.d. \pm 0.78 ) per day. Average intake of vegetables (excluding French fries and white potatoes) was 2.12 cups (s.d. \pm 2.37 ) per day. Table 2 provides demographic and fruit and vegetable intake results.

Interview participants held a variety of positions within American Indian communities. All participants' positions required that they interact with American Indian toddlers and/or families. Interview participants had a combined 57 years of experience working with the American Indian population. During content analysis, several themes emerged from the focus groups and interviews. Tables 3 and 4 depict themes that were compiled from the interviews and focus groups individually and sample quotes to illustrate these themes. When combined, the focus group and interview data yielded several concordant themes related to fruit and vegetablerelated information, motivation, and behavioral skills (see
Table 2 Focus group participant demographics and reported toddler fruit and vegetable intake

\begin{tabular}{|c|c|c|}
\hline Characteristic & $N^{\mathrm{a}}$ & Percentage \\
\hline \multicolumn{3}{|l|}{ Gender } \\
\hline Female & 42 & 93.3 \\
\hline Male & 3 & 6.7 \\
\hline \multicolumn{3}{|l|}{ Race } \\
\hline American Indian & 43 & 95.6 \\
\hline Other & 2 & 4.4 \\
\hline \multicolumn{3}{|l|}{ Education } \\
\hline Less than high school & 3 & 6.7 \\
\hline Some high school & 4 & 8.9 \\
\hline High school diploma/GED & 17 & 37.8 \\
\hline Some college & 13 & 28.9 \\
\hline College grad & 6 & 13.3 \\
\hline Post-college grad & 2 & 4.4 \\
\hline \multicolumn{3}{|l|}{ Employment } \\
\hline Full-time & 8 & 22.2 \\
\hline Part-time & 5 & 13.9 \\
\hline Retired & 6 & 16.7 \\
\hline Student & 8 & 22.2 \\
\hline \multirow[t]{2}{*}{ Unemployed } & 9 & 25.0 \\
\hline & Mean & s.d. \\
\hline Age (years) & 38.16 & 15.30 \\
\hline Number of kids in care & 3.44 & 2.88 \\
\hline Child fruit intake & 0.79 cups & 0.78 \\
\hline Child juice intake & 1.85 cups & 2.04 \\
\hline Child vegetable intake (- potatoes) & 2.13 cups & 2.37 \\
\hline Child potato intake & 0.40 cups & 0.48 \\
\hline
\end{tabular}

${ }^{\text {a }}$ Individual categories may not sum to 45 due to missing values

${ }^{\mathrm{b}}$ Percentage may sum to $>100$ due to rounding

Fig. 1 for a pictorial representation of these themes). Information-related themes included the benefits of fruits and vegetables, cooking, food safety, and quality. Motivation-related themes included parental and child attitudes, food security, and environmental supports. Behavioral-skill-related themes included cooking, gardening, and role modeling.

\section{Information: "If We Can Just Educate Ourselves so We Can Educate Our Children"}

Both focus group and interview participants communicated a need and a desire to increase knowledge regarding fruits, vegetables, and general healthy eating. Caregivers reported being confused about the variety of messages they hear in the media regarding "nutritious eating," which types of fruits and vegetables to purchase and the best ways to prepare certain fruits and vegetables. Interview participants communicated 
Table 3 Interview themes and illustrative quotes

\begin{tabular}{|c|c|}
\hline Theme & Quote \\
\hline Taste is key & $\begin{array}{l}\text { "They say, 'I know it's not gonna taste good, I } \\
\text { don't want that." }\end{array}$ \\
\hline Convenience wins & $\begin{array}{l}\text { "There's no preparing an actual meal for the } \\
\text { children and themselves. It's more fast food or } \\
\text { pizzas, hot dogs, convenience. And not } \\
\text { nutritious, either. Like a lot of pop." }\end{array}$ \\
\hline Food security & $\begin{array}{l}\text { "A lot of those junk foods are a lot cheaper to } \\
\text { buy and they still feed your family and that is } \\
\text { what they are looking to do is just to feed their } \\
\text { kids and fill them." }\end{array}$ \\
\hline All about education & $\begin{array}{l}\text { "I really feel it's about education. That's the } \\
\text { main thing. You know, they might have } \\
\text { grown up where their mom never cooked or } \\
\text { taught them how to prepare a meal or the } \\
\text { importance of eating together as a family." }\end{array}$ \\
\hline A community issue & $\begin{array}{l}\text { "Diabetes, obesity, this is a community problem, } \\
\text { a Native American problem." }\end{array}$ \\
\hline $\begin{array}{l}\text { Keeping the children } \\
\text { healthy }\end{array}$ & $\begin{array}{l}\text { "Just addressing the absolute importance of, } \\
\text { your child needs to be eating healthy. You } \\
\text { can't feed them garbage and expect them to } \\
\text { grow up." }\end{array}$ \\
\hline $\begin{array}{l}\text { Role modeling makes } \\
\text { a difference }\end{array}$ & $\begin{array}{l}\text { "One will start eating it and if he likes it then } \\
\text { another one will be like, 'Oh I like it too' and } \\
\text { they kind of follow the pack." }\end{array}$ \\
\hline Taking responsibility & $\begin{array}{l}\text { "I think they know it's important, but don't } \\
\text { know how to make it important." }\end{array}$ \\
\hline
\end{tabular}

that a lack of knowledge regarding dietary guidelines for children and cooking skills are issues that impact dietary intake among American Indian families.

Participants in both focus groups and interviews stated that, to improve intake of fruits and vegetables, educational programs need to include hands-on activities for children to get them involved with the preparation of fruits and vegetables. Caregivers requested information regarding specific health benefits of fruits and vegetables, gardening and expressed a desire to learn about new fruits and vegetables. As one focus group participant stated, "I don't even know what all of the vegetables are, so something to tell me this is what this is, this is how you make it, and this is what it is good for." Stakeholders concurred that educational programs should include detailed information regarding how to use different types of fruits and vegetables. Communicating this idea was one interview participant, who stated "I really feel it's education, that's the main thing... I think it's education all the way through. Teach them how to go to the grocery store. Teach them how to make a list."

One topic consistently expressed through the focus groups that was not communicated in the stakeholder interviews was the issue of food safety. Caregivers communicated concerns regarding best practices to keep their food from becoming harmful to their families. As one participant stated, "Some
Table 4 Focus group themes and illustrative quotes

\begin{tabular}{|c|c|}
\hline Theme & Quote \\
\hline Knowledge is power & $\begin{array}{l}\text { "I'd like to know, like the different things that } \\
\text { they can help, like, carrots with eyes, and they } \\
\text { say that, like some fruits and vegetables help, } \\
\text { like reduce the risk of cancers and stuff like } \\
\text { that." }\end{array}$ \\
\hline Support from others & $\begin{array}{l}\text { "My sister comes over and she doesn't like } \\
\text { tomatoes so she'll be like, 'Oh that's } \\
\text { disgusting" and then (my kids) look down and } \\
\text { then they won't eat it. And then I'm like } \\
\text { 'Thanks a lot."' }\end{array}$ \\
\hline Parental behaviors & $\begin{array}{l}\text { "When we eat, I'll make sure that we have } \\
\text { vegetables on our plate and I will eat it in front } \\
\text { of them." }\end{array}$ \\
\hline $\begin{array}{c}\text { Cooking versus } \\
\text { convenience }\end{array}$ & $\begin{array}{l}\text { "It's just so much easier if you can just open a } \\
\text { package of something and eat it." }\end{array}$ \\
\hline $\begin{array}{l}\text { Making healthy } \\
\text { foods palatable }\end{array}$ & $\begin{array}{l}\text { "Like we made peas and carrots and we had to put } \\
\text { like a little brown sugar in it otherwise they } \\
\text { wouldn't even try it." }\end{array}$ \\
\hline $\begin{array}{l}\text { Getting the kids } \\
\text { involved }\end{array}$ & $\begin{array}{l}\text { "Mine always say they helped so they want to } \\
\text { taste it. They will say, 'I helped make this, isn't } \\
\text { it delicious!" }\end{array}$ \\
\hline $\begin{array}{l}\text { Doing it for the } \\
\text { children }\end{array}$ & $\begin{array}{l}\text { "If we can just educate ourselves so we can } \\
\text { educate our children and teach them how to eat } \\
\text { right. You know, it'd be best for them. Healthy } \\
\text { and they will live longer I think." }\end{array}$ \\
\hline $\begin{array}{l}\text { Accessibility and } \\
\text { affordability }\end{array}$ & $\begin{array}{l}\text { "And a lot of times you have no transportation to } \\
\text { get to the store and you are spending all of your } \\
\text { money getting where you need to go and it's } \\
\text { horrible; because I have to tell those kids I } \\
\text { don't have enough money for you to have } \\
\text { vegetables at lunch." }\end{array}$ \\
\hline
\end{tabular}

(vegetables) are worse than others. You always hear about tomatoes and spinach, so I don't even buy them." Caregivers discussed that their primary concern related to food safety was in keeping their toddlers "from getting sick." While participants did not express specific foodborne illnesses of concern, they did express desire to learn more about ways to keep their toddlers safe from foodborne illnesses in general.

\section{Motivation: "I Think the Circle Is Just Broken"}

Caregivers communicated numerous aspects of motivation throughout the focus group discussions. Personal attitudes toward fruits and vegetables were discussed and a wide variety of opinions on the topic were expressed. One focus group participant stated, "When I think of fruits and vegetables, my mouth just starts watering." In comparison, another participant stated, "I don't eat no vegetables." A broad range of toddler opinions regarding fruits and vegetables were also discussed, from "He loves all of his vegetables" to "It's a struggle, I can't even get my son to try a tomato." Caregivers communicated 


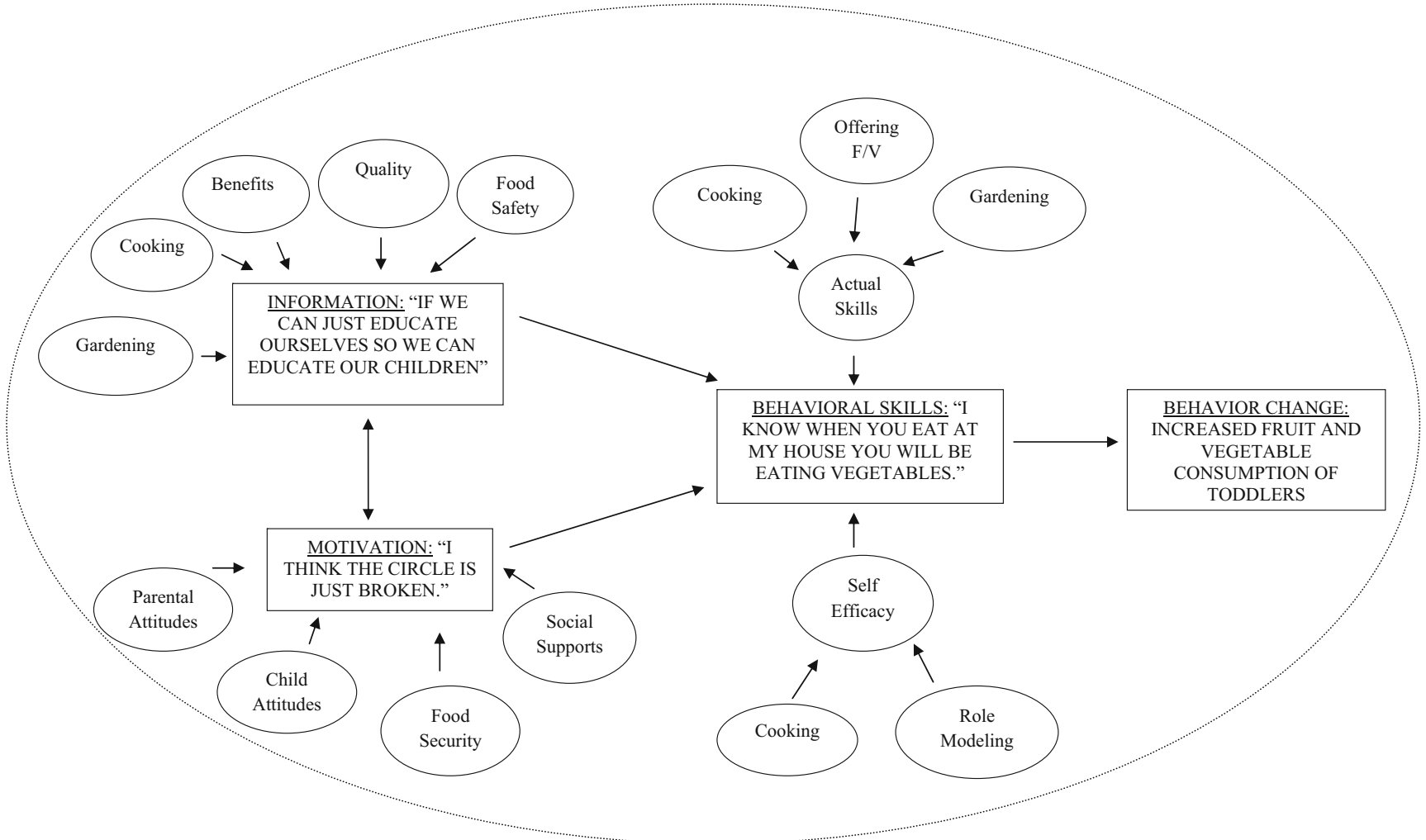

Fig. 1 IMB model with themes from focus groups and interviews

that taste and other sensory aspects of fruits and vegetables play a large role in determining whether or not their toddler will try a new fruit or vegetable. As one participant stated, "My daughter hates the smell and the texture and the taste. Pretty much everything."

Community stakeholders echoed these challenges and communicated that attitudes around taste are an issue when offering healthy foods to both caregivers and toddlers. One stakeholder communicated one such experience, "I was just talking to a parent last week who said, 'I know if it tastes good, it's not good for me, and if it's healthy, it's gonna taste bad.' It's not just kids, it's everybody."

Both focus group and interview participants discussed social influences to offering healthful foods such as fruits and vegetables to young children. Study participants discussed lack of peer support as a challenge to providing fruits and vegetables to their young children. As one focus group participant stated, "I am the only one in my family, in my house, that cares about fruits or vegetables at all... and that is just so frustrating to me." Caregivers discussed that family and peer networks were especially important in ensuring their toddlers received a consistent message regarding fruits, vegetables, and healthy eating. As summarized by one participant, "They hear them say, 'I don't want to eat that,' or at a certain cousins house and they hear them talk about a certain vegetable that they used to eat and then they won't eat it anymore. It makes it so hard."
In contrast, the social supports that were discussed by community stakeholders focused on the roles that elders and the broader American Indian community can play in addressing the health of its members. As one stakeholder put, "Food means a great deal to them, it is an honor...but I think the circle is just broken. But not one person is going to accomplish it and they need to see that multiple sources care." In discussing the health of American Indian toddlers, stakeholders framed it as a "community problem" that requires support from throughout the community.

Both caregivers and community stakeholders discussed the role that schools and daycares can play in increasing fruit and vegetable consumption. One caregiver offered, "They do give them snacks at school, like fruits and vegetables, but it's not as often of the time. They really should give them more." This sentiment was echoed by a community stakeholder who suggested, "It has to happen, I think, in the schools."

Numerous aspects of food security were discussed in both the focus groups and interviews with stakeholders. Caregivers communicated that accessibility and affordability limits them in their purchases of fruits, vegetables, and healthful foods in general. "And a lot of times you have no transportation to get to the store and you are spending all of your money getting where you need to go and it's horrible, because I have to tell those kids I don't have enough money for you to have vegetables at lunch."

Community stakeholders discussed similar issues with food security among the American Indian families they serve. 
As a result of limited availability and limited budgets, stakeholders see caregivers providing foods that are lacking in nutritional value. As stated by one interview participant, "They don't have access to a store so they send their kids to the convenience store to buy chips and pop and what is cheap to keep their bellies full."

\section{Behavioral Skills: "I Want to Be More Self-Sufficient with Fruits and Vegetables"}

Focus group participants discussed numerous behavioral skills imperative for offering their toddlers fruits and vegetables, which included actual skill-sets and self-efficacy. Caregivers discussed perceived and actual cooking skills, gardening, role modeling, and ability to provide fruits and vegetables to their children. In regard to cooking self-efficacy, one focus group participant stated, "I can follow a recipe and it doesn't turn out half the time if I'm not familiar with cooking it." Focus group participants indicated that they often prepare the same meals repeatedly and "get into ruts" because they lack confidence to try new recipes and offer a variety of different fruits and vegetables to their family.

Caregivers discussed the importance of role modeling and commented on their skills in serving as an example in eating fruits and vegetables. For example, "My daughter, she'll see and she'll be kind of checking it out and be like, ok, if mom is doing it so let me try this." Caregivers discussed that their children oftentimes serve as role models for them, and that, at times, it is after their child's urging that they purchase or prepare a new fruit or vegetable for the family.

Stakeholders also found role modeling important and discussed how eating norms are established by parents, "They think, 'Well I didn't eat this and that when I was growing up and I am fine so my kids will be fine.' They just aren't seeing it." This mindset, stakeholders suggested, is a difficult barrier in addressing nutrition behaviors among American Indian families.

Both caregivers and stakeholders discussed gardening programs as an option to improve availability and defer the cost of fruits and vegetables. Caregivers expressed a desire to grow, freeze, and can vegetables in an effort to become "more self-sufficient." Community stakeholders suggested that these programs have been effective at addressing numerous aspects related to fruit and vegetable intake, "They were learning the value of hard work and exercise with gardening... and what's good to eat and how to eat it."

\section{Keeping the Children Healthy: "When the Kids Eat Better, They Have a Better Chance"}

A message heard consistently from caregivers and community stakeholders was that, above all, they are concerned about the health of their children. Caregivers discussed their own personal struggles with diabetes and their desires to keep their toddlers from having these same issues, "Because of my diabetes, I am trying to keep my kids healthier so they don't get it. That's my main goal, that they don't get it."

Community stakeholders also echoed these concerns regarding diabetes and discussed efforts to educate children about how to reduce their risk. One stakeholder stated, "Now we do youth diabetes education classes, we are starting earlier." A health issue that was not discussed among caregivers that weighed heavily on the minds of stakeholders was that of dental health. As expressed by one stakeholder, "The kids' teeth are poor. They come in here with a lot of cavities. I suspect it's a result of bottles, with juice and stuff. Probably junk food too."

Study participants communicated that a complex interaction of factors takes place to impact children's fruit and vegetable consumption. As one community stakeholder concisely stated, "It's the knowledge and desire to cook healthy foods for your family and the access to get it. Like, it's a hand in hand thing. If I want to cook healthy meals for my family but I don't have the resources and support to do it, I'm not going to do it."

\section{Discussion}

This study used qualitative methods to explore fruit and vegetable-related perceptions among caregivers of American Indian toddlers and stakeholders in American Indian communities throughout two tribal reservations and three urban settings servicing the American Indian community in Nebraska. Caregiver and stakeholder perceptions about fruits, vegetables, and healthful eating in general provided valuable insights that may be used in developing educational programs tailored to the American Indian community.

Caregivers reported the fruit and vegetable consumption of their children, with an average reported intake of 0.78 cups per day of fruit and 2.12 cups per day of vegetables. This is higher than what studies in similar populations have reported $[14,15]$ and indicates that study participants have children who are meeting the US Department of Agriculture's 2010 Dietary Guidelines for Americans for vegetables but not for fruits [42]. However, it is also possible that study participants overestimated their child's intake of vegetables and/or fruits, as has been reported as a challenge with food frequency questionnaires [43]. There was a wide range in the age of the focus group participants (15 to 64 years old), with several grandmothers reporting as caregivers of the toddlers.

A topic of discussion throughout the focus groups and interviews was that of the accessibility and affordability of fruits and vegetables. The US Department of Agriculture (USDA) defines a food desert as "urban neighborhoods and 
rural towns without ready access to fresh, healthy, and affordable food [44]." According to the USDA's Economic Research Service Food Service Locator [45], four of the five sites where focus groups took place are considered food deserts and in need of improved environmental supports to increase access to fresh fruits and vegetables.

Caregivers and community stakeholders in this study discussed several challenges to providing fruits and vegetables to toddler-age children, including child attitudes toward fruits and vegetables, family and peer support, food insecurities, self-efficacy, and skills to prepare fruits and vegetables. Caregivers also discussed the role that their own attitudes toward fruits and vegetables and the knowledge of the benefits of consumption of fruits and vegetables can have in offering fruits and vegetables to their family. These results are consistent with previously conducted studies with parents of preschool-age children $[46,47]$ which concluded that barriers to fruit and vegetable consumption among children include availability, cost, role modeling, time limitations, and knowledge of preparation.

These results are also consistent with findings from studies that have been conducted with American Indian individuals of varying age groups. For adolescent-age American Indian children, perceptions of overall health, social, and family supports play a large role in fruit and vegetable intake [11]. For the primary grocery shopper in American Indian families, self-efficacy and knowledge has predicted buying behaviors of both healthful and lessnutritious food items [22]. Previously conducted qualitative research among American Indian adults also revealed that environmental backing, such as support from schools and peers, as well as relevant knowledge about healthful eating and access to nutrient dense foods, all impact perceptions of nutritious foods [22].

Caregivers of American Indian toddlers expressed concerns regarding their young child's risk for type II diabetes. These are valid concerns, with American Indian youth at nine times the risk of a type II diabetes diagnosis compared to nonHispanic whites [48]. However, this is the first study to uncover caregiver concerns regarding their toddler-age child's risk for developing diabetes through a qualitative design.

Community stakeholders expressed a variety of ideas around the health and wellness of American Indian toddlers that were congruent with the topics expressed through the caregiver focus groups. Concerns surrounding dental caries, however, were not shared by caregivers. Stakeholders have cause for concern as it has been estimated that the prevalence of early childhood caries among American Indian children is approximately 300 times higher than the US all-race prevalence, with approximately $25.0 \%$ of American Indian children requiring full mouth restoration by the time they enter kindergarten and an all-race prevalence of early childhood caries of $8.0 \%$ [49].
The IMB model suggests that targeted interventions to improve the fruit and vegetable intake of American Indian toddlers should address deficits in information, motivation, and behavioral skills of caregivers [25]. While numerous fruitand vegetable-based interventions have been developed and implemented for a wide variety of audiences [50-54], few interventions have targeted American Indian children. Those that have been implemented have been somewhat narrow in scope and focused specifically on improving self-efficacy [55], increasing school and family supports [56], and addressing cultural barriers [57].

While culture was not a specific topic of discussion among caregivers in the focus groups, it was consistently discussed among community stakeholders. The idea that nutrition and health-related issues are issues that warrant community attention has been expressed in previous research $[58,59]$. The concept of community as a "circle" as communicated by one stakeholder is also not a new concept, especially as it relates to American Indian children. The Circle of Courage model [60] has been used to develop empowerment programs among American Indian youth. The circle is broken into four sections that focus on belonging, mastery, independence, and autonomy. The shape of the circle is important, as there are no sharp edges and serves to guide children into a community of understanding and compassion. As community stakeholders in this study communicated, it is important to consider these aspects of culture in developing future nutrition interventions for American Indian families with toddlers. The IMB model from this study (Fig. 1) is outlined by a circle to represent the interaction between culture and all findings of this study.

Based on findings from this current study, future interventions to improve fruit and vegetable intake among American Indian toddlers should address several key topics. Caregivers suggested that programs should include information regarding recommendations for amounts and types of fruits and vegetables to be provided to their children, ways to keep food safe from foodborne illnesses, and different recipes. Caregivers also suggested that hands-on cooking classes and activities for their children would help to improve their children's perceptions of fruits and vegetables. Gardening programs may be effective at improving caregivers' and children's attitudes toward fruits and vegetables and addressing issues with food security. These programs should focus on building community awareness and obtaining support from key leaders in the community regarding nutrition-related health issues, including elders and tribal officials.

This qualitative study is one of the first pieces of research that has compared and contrasted qualitative findings from caregivers of American Indian toddlers and American Indian community stakeholders regarding nutrition-related perceptions. While this study had a relatively small sample size $(N=55)$, this is typical of focus group research [36] and qualitative research in general [34]. Additionally, while the 
goal of qualitative research is to explore complex issues indepth and not necessarily to generalize [34], study participants represented at least four major tribes representative of the Great Plains, including Omaha, Santee Sioux, Ponca, and Winnebago [61].

While the focus group facilitator and interviewer was not of American Indian descent, trust had been established with many of the participants by the facilitator's attendance at numerous health fairs and events at the community centers and reservations. This ensured that participants felt comfortable openly discussing thoughts and feelings about personal topics. Additionally, although study participants were encouraged to give open and honest answers, the nature of the topics being discussed may have lent themselves to provide optimistic responses. While the interviewer regularly ensured participants that there were no right or wrong answers, some participants may have answered more positively as a result of social desirability.

This study provides detailed insights into perceptions of fruits, vegetables, and general nutrition perceptions among caregivers of American Indian toddlers and stakeholders in American Indian communities. Future research should apply qualitative methods to explore the issue of fruit and vegetable consumption among American Indian children in other tribal communities. Research should also strive to assess the IMB model's applicability to fruit and vegetable consumption among American Indian toddlers to a quantitative assessment to generalize the findings from this and future qualitative studies and to inform the development of educational programs to increase fruit and vegetable consumption among the American Indian population.

Acknowledgments This study was supported by the Transdisciplinary Obesity Prevention grant through South Dakota State UniversityUSDepartment of Agriculture (National Institute of Food and Agriculture) 2011-67002-30202.

Conflict of Interest Rachel C. Sinley and Julie A. Albrecht declare that they have no conflicts of interest.

Informed Consent All procedures followed were in accordance with the ethical standards of the responsible committee on human experimentation (institutional and national) and with the Helsinki Declaration of 1975, as revised in 2000 (5). Informed consent was obtained from all patients for being included in the study.

\section{References}

1. Fryer CD, Carroll MD, Ogden CL. Prevalence of overweight, obesity and extreme obesity among adults: United States, 1960-1962 through 2011-2012. Health E-Stat. 2014. http://www.cdc.gov/nchs/ data/hestat/obesity adult 11 12/obesity_adult 11 12.pdf. Accessed 8 Nov 2014.

2. Freedman DS, Khan LK, Dietz WH, Srinivasa SR, Berenson GS Relationship of childhood obesity to coronary heart disease risk factors in adulthood: the Bogalusa heart study. Pediatrics. 2001;108(3):712-8.

3. Liao Y, Bang D, Cosgrove S, Dulin R, Harris Z, Stewart A, Taylor A, White S, Yatabe G, Liburd L, Giles W. Surveillance of health status in minority communities: Racial and ethnic approaches to community health across the U.S. (REACH U.S.) risk factor survey, United States, 2009. MMWR Surveill Summ. 2011;60(6):1-44.

4. Holm JE, Vogeltanz-Holm N, Poltavski D, McDonald L. Assessing health status, behavioral risks, and health disparities in American Indians living on the Northern Plains of the U.S. Public Health Rep. 2010;125:68-78.

5. Denny CH, Holtzman D, Cobb N. Surveillance for health behaviors of American and Alaska Natives: Findings from the Behavioral Risk Factor Surveillance System, 1997-2000. MMWR Surveill Summ. 2003;52(SS07):1-13.

6. Centers for Disease Control and Prevention. Trends in the prevalence of extreme obesity among US preschool-aged children living in lowincome families, 1998-2010. JAMA. 2012;308(24):2563-2565.

7. Franks PW, Hanson RL, Knowler WC, Sievers ML, Bennett PH, Looker HC. Childhood obesity, other cardiovascular risk factors, and premature death. N Eng J Med. 2010;362:485-93.

8. Lindberg SM, Adams AK, Prince RJ. Early predictors of obesity and cardiovascular risk among American Indian children. Matern Child Health J. 2012;16:1879-86.

9. Gray A, Smith C. Fitness, dietary intake, and body mass index in urban Native American youth. J Am Diet Assoc. 2003;103:1187-91.

10. Fialkowski MK, Okoror TA, Boushey CJ. The relevancy of community-based methods: using diet within Native American and Alaska Native adult populations as an example. Clin Trans Med. 2012;5:295-300.

11. Story M, Neumark-Sztainer D, Resnick M, Blum RM. Psychosocial factors and health behaviors associated with inadequate fruit and vegetable intake among American- Indian and Alaska-Native adolescents. J Nutr Educ. 1998;30(2):100-6.

12. LeMaster PL, Connell CM. Health education interventions among Native Americans: a review and analysis. Health Educ Behav. 1994;121:521-38.

13. Cobb N, Espey D, King J. Health behaviors and risk factors among American Indians and Alaska Natives, 2000-2010. Am J Public Health. 2014;104(S3):S481-9.

14. LaRowe TL, Adams AK, Jobe JB, Cronin KA, Vannatter SM, Prince RJ. Dietary intakes and physical activity among preschool-Aged children living in rural American Indian communities before a family-based healthy lifestyle intervention. J Am Diet Assoc. 2010;110:1049-57.

15. Stroehla BC, Malcoe LH, Velie EM. Dietary sources of nutrients among rural Native American and white children. J Am Diet Assoc. 2005;105:1908-16

16. Panagiotakos D, Chrysohoou C, Pitsavos C, Stefanadis C. Association between the prevalence of obesity and adherence to the Mediterranean diet: the ATTICA study. Nutrition. 2006;22: 449-56.

17. Lock K, Pomerleau J, Causer L, Altmann DR, McKee M. The global burden of disease attributable to low consumption of fruit and vegetables: Implications for the global strategy on diet. B World Health Organ. 2005;83(2):100-8.

18. World Health Organization. Diet, nutrition and the prevention of chronic diseases. http://www.who.int/dietphysicalactivity/ publications/trs916/en/ (2003). Accessed 13 Jul 2013.

19. Van Duyn MS, Pivonka E. Overview of the health benefits of fruits and vegetable consumption for the dietetics professional: selected literature. J Am Diet Assoc. 2000;100:1511-21.

20. Fisher JD, Fisher WA. Changing AIDS-risk behavior. Psychol Bull. 1992;111:455-74.

21. Gittelsohn J, Anliker JA, Sharma S, Vastine AE, Caballero B, Ethelbah B. (2006). Psychosocial determinants of food purchasing 
and preparation in American Indian households. J Nutr Educ Behav. 2006;38:163-8.

22. Cantrell BG. Access and barriers to food items and food preparation among Plains Indians. Wicazo Sa Rev. 2001;16(1):65-74.

23. Fisher WA, Fisher JD. Understanding and promoting sexual and reproductive health behavior: theory and method. In: Rosen R, Davis C, Ruppel H, editors. Annual review of sex research. Mount Vernon: Society for the Scientific Study of Sexuality; 1999.

24. Fisher JD, Fisher WA, Shuper PA. The information-motivationbehavioral skills model of HIV preventive behavior. In: DiClemente R, Crosby R, Kegler M, editors. Emerging theories in health promotion practice and research. San Francisco: Jossey-Bass; 2009.

25. Hingle M, Beltran A, O'Connor T, Thompson D, Baranowski J, Baranowski T. A model of goal directed vegetable parenting practices. Appetite. 2012;58:444-9.

26. Kudlová E, Schneidrová D. Dietary patterns and their changes in early childhood. Cent Eur J Pub Health. 2012;20(2):126-34.

27. Vereecken C, Rovner A, Maes L. Associations of parenting styles, parental feeding practices and child characteristics with young children's fruit and vegetable consumption. Appetite. 2010;55:589-96.

28. Anonymous. The importance of community participation in the prevention of obesity among American Indian children. J Sport Exercise Psy. 2013;35(2):226.

29. Simmons T, Dye JL. Grandparents living with grandchildren: 2000. http://www.census.gov/prod/2003pubs/c2kbr-31.pdf. Accessed 2 Jun 2014.

30. Mutchler JE, Baker LA, Lee S. Grandparents responsible for grandchildren in Native-American families. Soc Sci Q. 2007;88(4): 990-1009.

31. Edwards ED, Drews J, Seaman JR, Edwards ME. Community organizing in support of self-determination within Native American communities. J Multicult Soc Work. 1994;3(4):43-60.

32. United States Census Bureau. (2012). The American Indian and Alaska Native population: 2010 http:/www.census.gov/prod/ cen2010/briefs/c2010br-10.pdf. Accessed 8 Nov 2013.

33. United States Census Bureau. (2012). State and county quickfacts. http://quickfacts.census.gov/qfd/states/31000.html. Accessed 8 Nov 2013.

34. Creswell JW. Educational research: Planning conducting, and evaluating quantitative and qualitative research. 2nd ed. Upper Saddle River: Pearson Education; 2005.

35. Thompson FE, Subar AF, Smith AF, Midthune D, Radimer KL, Kahle LL. Fruit and vegetable assessment: performance of 2 new short instruments and a food frequency questionnaire. J Am Diet Assoc. 2002;102:1764-72.

36. Krueger RA, Casey MA. Focus groups: a practical guide for applied research. 3rd ed. Thousand Oaks: Sage; 2000.

37. Krefting L. Rigor in qualitative research: the assessment of trustworthiness. Am J Occup Ther. 1991;45:214-22.

38. Merriam SB. Qualitative research: a guide to design and implementation. San Francisco: Wiley; 2009.

39. Krippendorff K. Content analysis: an introduction to its methodology (2nd ed). Thousand Oaks, CA: Sage: 2013.

40. Creswell JW. Qualitative inquiry and research design: choosing among five approaches. 3rd ed. Thousand Oaks: Sage; 2013.

41. National Cancer Institute. Scoring the All-Day Fruit and Vegetable Screener. http://appliedresearch.cancer.gov/diet/screeners/fruitveg/ scoring/allday.html. Accessed 21 Apr 2014.

42. United States Department of Agriculture (USDA). Dietary guidelines for Americans 2010. www.dietaryguidelines.gov/. Accessed $25 \mathrm{Jul}$ 2014.
43. Pearson N, Atkins AJ, Biddle SJ, Gorely T, Edwardson C. Patterns of adolescent physical activity and dietary behaviours. Int J Behav Nutr Phys. 2009;6:45.

44. United States Department of Agriculture. Food Deserts. https://apps. ams.usda.gov/fooddeserts/foodDeserts.aspx. Accessed 25 Aug 2014.

45. United States Department of Agriculture. Food Access Research Atlas. http://www.ers.usda.gov/data/fooddesert. Accessed 25 Aug 2014.

46. Tucker P, Irwin JD, He M, Bouck LMS, Pollett G. Preschoolers' dietary behaviors: parents' perspectives. Can J Diet Pract Res. 2006;67:67-71.

47. Shriver LH, Hildebrand D, Austin H. Determinants of fruit and vegetable availability in Hispanic Head Start families with preschool-aged children living in an urban Midwestern area. J Nutr Educ Behav. 2010;42:299-306.

48. SEARCH for Diabetes in Youth Study. http://ncbi.nih.gov/pubmed/ 17015542. Accessed 25 Aug 2014

49. American Dental Association. 2010 symposium on early childhood caries in American Indian and Alaskan Native children. http://www. ada.org/ /media/ADA/Education\%20and\%20Careers/Files/2010 ecc symposium report.ashx. Accessed 25 Aug 2014.

50. Kothe EJ, Mullan BA, Butow P. Promoting fruit and vegetable consumption: testing an intervention based on the theory of planned behaviour. Appetite. 2012;58:997-1004.

51. Gentile DA, Welk G, Eisenmann JC, Reimer RA, Walsh DA, Russell DW, et al. Evaluation of a multiple ecological level child obesity prevention program: switch what you do, view, and chew. BMC Med. 2009;7:49.

52. Heim S, Stang J, Ireland M. A garden pilot project enhances fruit and vegetable consumption among children. J Am Diet Assoc. 2009;109; $1220-6$.

53. Wolf RL, Lepore SJ, Vandergiff JL, Basch CE, Yaroch AL. Tailored telephone education to promote awareness and adoption of fruit and vegetable recommendations among urban and mostly immigrant black men: a randomized controlled trial. Prev Med. 2009;48:32-8.

54. Di Noia J, Contento IR, Prochaska JO. Computer-mediated intervention tailored on transtheoretical model stages and processes of change increases fruit and vegetable consumption among urban AfricanAmerican adolescents. Am J Health Promot. 2008;22:336-41.

55. Rinderknecht K, Smith C. Social cognitive theory in an after-school nutrition intervention for urban Native American youth. J Nutr Educ Behav. 2004;36:298-304.

56. Caballero B, Clay T, Davis SM, Ethelbah B, Holy Rock B, Lohman T, et al. Pathways: a school-based, randomized controlled trial for the prevention of obesity in American Indian schoolchildren. Am J Clin Nutr. 2003;78:1030-8.

57. LaRowe TL, Wubben DP, Cronin KA, Vannatter SM, Adams AK. Development of a culturally appropriate, home-based nutrition and physical activity curriculum for Wisconsin American Indian families. Prevent Chron Dis. 2007;4(4):A109.

58. Osterkamp LK, Longstaff L. Development of a dietary teaching tool for American Indians and Alaskan Natives in Southern Arizona. J Nutr Educ Behav. 2004;36:272-4.

59. Roubideaux YD, Moore K, Avery C, Muneta B, Knight M, Buchwald D. Diabetes education materials: recommendations of tribal leaders, Indian health professionals, and American Indian community members. Diabetes Educ. 2000;26:290.

60. Brendtro LK, Brokenleg M, Van Bockern S. The circle of courage and positive psychology. Reclaiming Child Youth. 2005;14(3):130-6.

61. United States Bureau of Reclamation. List of Tribes in the Great Plains Region by Area Office. http://www.usbr.gov/native/regions/ gp/GP-Tribes.pdf?region=GP. Accessed 23 Aug 2014. 